\title{
A filosofia da linguagem bakhtiniana e sua tridimensionalidade verbivocovisual
}

DOI: http://dx.doi.org/10.21165/el.v49i2.2691

\section{Luciane de Paular José Antonio Rodrigues Luciano²}

\section{Resumo}

Este artigo tem por escopo compreender a concepção de linguagem proposta na elaboração da filosofia da linguagem bakhtiniana, em especial, a partir das obras de Bakhtin, ECV (2011); de Medviédev, MFEL (2012); e de Volóchinov, MFL (2017)³. A hipótese apresentada é a de que, para pensar a relação entre sujeito e signo, o Círculo utilizou-se da palavra, entendida de forma alargada, isto é, como linguagem tridimensional, a qual Paula cunhou verbivocovisual, uma vez que se articula e realiza-se na interrelação das dimensões verbal (semântica), vocal (sonora) e visual (imagética). Para o desenvolvimento deste estudo, utilizamos o método dialético-dialético (PAULA, FIGUEIREDO, PAULA, 2011) e, por cotejo, os textos entre si e entre outras obras do Círculo, bem como entre conceitos e áreas das quais advêm, contextualizados. Com isso, além da noção de linguagem, procuramos refletir acerca da pertinência do pensamento bakhtiniano como aporte teórico para análise de enunciado visual, verbal, sonoro e/ou sincrético.

Palavras-chave: círculo de Bakhtin; verbivocovisualidade; Filosofia da Linguagem.

\footnotetext{
1 Universidade Estadual Paulista "Júlio de Mesquita Filho" (UNESP), Assis, São Paulo, Brasil; lucianedepaula1@gmail.com; https://orcid.org/0000-0003-1727-0376

2 Universidade Estadual Paulista "Júlio de Mesquita Filho" (UNESP), Araraquara, São Paulo, Brasil; trodrigues01.tr@gmail.com; https://orcid.org/0000-0003-1748-8279

3 Respectivamente, Estética da Criação Verbal, O Método Formal nos Estudos Literários e Marxismo e Filosofia da Linguagem.
} 


\section{La philosophie du langage bakhtinienne et sa tridimensionnalitée verbivocovisuelle}

\section{Résumé}

Cette article a l'intention de comprendre la conception du langage proposée dans l'élaboration de la philosophie du langage bakhtinienne, surtout, à partir des oeuvres de Bakhtine, ECV (2011), de Medviedev, MFEL (2012); et Volochinov, MFL (2017)4. L'hypothèse est que, pour penser la relation entre le sujet et le signe, le Cercle a utilisé la parole, entendue largement, comme langage tridimensionalle, laquelle Paula a denominée verbivocovisuelle, puisque s'articule et se realise dans l'interdépendance des dimensions verbale (sémantique), vocale (sonore) et visuelle (imagétique). Pour le développement de cet étude, nous considérons la méthode dialétique-dialogique (PAULA et al, 2011) et, par rapport, les textes entre eux et entre autres oeuvres de Cercle, ainsi que entre les concepts et les domines desquels se proviennent situés. Plus de la notion de langage, nous recherchons réflechir la pertinence de la pensée bakhtinienne comme fondement théorique pour l'analyse du enoncé visuel, verbal, vocal et/ou syncrétique.

Mots-clés: cercle de Bakhtine; verbicovovisuelitée; Philosophie du langage.

\section{Introdução}

Ao eleger a palavra como objeto de reflexão acerca da relação entre sujeito e língua(gem), o grupo de intelectuais, denominado Círculo de Bakhtin, toma a literatura, e mais especificamente o romance, para realizar essa tarefa, pois, de acordo com o pensamento bakhtiniano, "o objeto fundamental, 'especificador' do gênero romanesco, que cria sua originalidade estilística, é o falante e sua palavra" (BAKHTIN, 2015, p. 124). Ademais, recordamos que, no período da União Soviética - contexto de produção, circulação e recepção dessa teoria -, a literatura era considerada "o mundo real" (EMERSON, 2003) diante da perseguição às Ciências Humanas. Assim, tendo amplo repertório da tradição literária russa e ocidental, os pensadores russos puderam estudar as diferenças, o embate de vozes, muitas vezes assimétrico, e as valorações por essa prosaística.

Nesse sentido, propomos, neste artigo, analisar e compreender como o Círculo se apoia na tradição literária para elaborar sua concepção de Palavra (ou linguagem), que entendemos de forma tridimensional, que Paula (2017a) cunhou verbivocovisual ${ }^{5}$. A hipótese é que

4 Respectivement, Esthétique de la Création Verbale, La Méthode Formelle en Littérature et Le Marxisme et la Philosophie du Langage.

5 Concepção que está em desenvolvimento a partir do projeto trienal (2017-2019) denominado Verbivocovisualidade: uma abordagem bakhtiniana tridimensional da linguagem. Tal proposta teóricometodológica pode ter seus primeiros apontamentos em Paula e Serni (2017) e Paula (2017a). 
os intelectuais se debruçaram sobre a palavra, entendida de forma alargada, ou seja, tridimensionalmente, uma vez que ela se articula e realiza na interrelação das dimensões verbal (semântica), vocal (sonora) e visual (imagética), e que a verbivocovisualidade constitui a linguagem em qualquer materialidade enunciada, com maior ou menor vigor, como potencialidade a ser explorada, a depender do projeto arquitetônico autoral e genérico realizado. Entendemos essa tridimensionalidade como a proposta dialógica de linguagem deste Círculo russo. Por esse viés é que podemos perceber alguns conceitos utilizados por Bakhtin, Medviédev e Volóchinov para conceber os fenômenos da linguagem, tomada em dois aspectos: como concepção e como materialização enunciativa. Concepções como entoação, imagem do autor, voz, polifonia, arquitetônica, entre outras, advindas de outros campos do pensamento, configuram metaforicamente a noção de linguagem do Círculo, com sua maior característica, a dialogia (entre as dimensões, os sistemas, os enunciados e os sujeitos).

Pretendemos apresentar como essa junção entre as dimensões já aparece, ora mais ora menos evidenciado, ao longo da tradição literária, desde as primeiras reflexões na Grécia Antiga, na Arte Poética, de Aristóteles, até a modernidade, em T. S. Elliot, Mallarmé, James Joyce e a Poesia Concreta, passando pelo Trovadorismo e pelo Romantismo. Compreenderemos como esse percurso na história da literatura pode servir de apoio para a concepção de linguagem bakhtiniana, chegando mesmo a influenciar os estudos da linguagem no século XX.

No desenvolvimento desse estudo, além da abordagem histórica na tradição literária, objeto de estudo do Círculo, partimos de três obras bakhtinianas: Marxismo e Filosofia da Linguagem (2017), de Volóchinov; O Método Formal nos Estudos Literários (2012), de Medviédev; e Estética da Criação Verbal (2011), de Bakhtin; para compreender se a concepção se dá dialogicamente entre os autores.

O método utilizado é o que Paula et al. (2011) denominou de dialético-dialógico acerca do pensamento bakhtiniano, pois consideramos o corpus em constante relação com outros enunciados (cotejo), que respondem ou são respondidos no elo da cadeia discursiva. Tomamos as obras em relação entre si e entre outros textos, do Círculo e de outros teóricos, bem como entre conceitos e áreas das quais advêm, de maneira situada.

Esperamos, além da noção de linguagem para os estudiosos russos, refletir acerca da pertinência da filosofia bakhtiniana como aporte teórico-filosófico para análises de enunciados visuais, vocais/sonoros e ou sincréticos, na relação com a materialidade verbal, sobre a qual o Círculo de Bakhtin se debruçou e a colaboração para a área é a justificativa que pauta a relevância deste estudo. 


\section{A interdependência das dimensões verbivocovisuais na tradição literária}

Uma das primeiras relações entre linguagens pode ser encontrada na Arte Poética (2008), de Aristóteles. Nela, o filósofo grego inclui a música [melopoiia] como parte constitutiva da tragédia, de modo a defini-la como

[...] a imitação de uma acção elevada e completa, dotada de extensão, numa linguagem embelezada por formas diferentes em cada uma das suas partes, que se serve da acção e não da narração e que, por meio da compaixão e do temor, provoca a purificação de tais paixões. (ARISTÓTELES, 2008, 1449b 24-28, p. 4748 , grifos nossos).

E, imediatamente, esclarece que, por "linguagem embelezada" entende aquela que "tem ritmo, harmonia [e canto]" (idem, 1449b 29-30, p. 48), isto é, a força expressiva, pois, das partes que constituem a tragédia e seu embelezamento, para o filósofo grego, a música é a mais elevada, pois, junto com a elocução, por meio dela se realiza a imitação/mimese. Por essa lógica é que a presença do coro (ou canto coral) ganha importância na tragédia. Para Aristóteles, esse elemento deve ser considerado um personagem associado à ação, que tem a função de servir de interlúdio, ou seja, de marcar o início e o fim dos episódios na tragédia e dar unidade ao enredo.

A importância da música na tragédia se volta à beleza e esta reside na dimensão da ordem e da justeza, como o próprio Aristóteles afirma em sua obra. A música garante essa linguagem embelezada por servir de ordenamento e harmonia ao todo.

Essa relação entre música e poesia, de acordo com a obra, aparece em outros gêneros. Além da presença de coro em outros gêneros, como na comédia e na epopeia, a própria poesia lírica, a princípio, foi constituída da matéria verbal acompanhada por um instrumento, a lira, da qual advém o nome dessa modalidade de poesia.

Em relação à dimensão visual, Aristóteles pouco, ou quase nada, fala, exceto em determinada passagem em seu texto, na qual compara os caracteres [ethe ${ }^{6}$ à pintura. Se o enredo é o princípio, a alma da tragédia, esta, por sua vez, revela - pois trata das ações do indivíduo - os caracteres, ou seja, as imagens que temos de quem pratica atos. Nesse sentido é que o pensador grego afirma ser "algo semelhante ao que se vê na pintura: se alguém trabalhasse com as mais belas tintas, todas misturadas, não agradaria tanto

6 Plural de ethos. 
como se fizesse o esboço de uma imagem" (1450b 1)7. Aqui, portanto, identificamos uma primeira articulação das dimensões verbal, sonora e visual, se não totalmente consciente e como parte de um tratado, mas como um potencial indício da presença de uma linguagem geral que organiza as diversas formas de realização, permitindo integrálas de maneira orgânica; bem como vemos o preceito grego de supremacia da alma, ou seja, da razão sobre o comportamento, de modo a pautar nossa imagem social, e que deve aparecer nas produções artísticas como condição de instrução moral e de beleza.

Se tal relação entre pintura e poesia não foi tão aprofundada por Aristóteles, o foi por Horácio, poeta latino. Ao elaborar seu conceito de Ut pictura poesis, este poeta proporcionou bases para uma tradição que será fundamental para o movimento romântico e os posteriores, do século XIX em diante. Assim expõe o poeta:

A poesia é como a pintura, uma te cativa mais, se te deténs mais perto; outra, se te pões mais longe; esta prefere a penumbra; aquela quererá ser contemplada em plena luz, porque não teme o olhar penetrante do crítico; essa agradou uma vez; essa outra, dez vezes repetida, agradará sempre. (HORÁCIO, 2005, 361-365, p. 65).

Essa comparação da poesia como pintura sintetiza e ilustra a preocupação do tratadista latino de uma obra literária que seja pragmática (doce e agradável), harmônica, proporcional, seguidora do decoro e de uma unidade e que seja clara (tal como a pintura). Além disso, observamos, na Arte Poética horaciana, instruções bem objetivas à presença do coro na poesia dramática e de como ele pode ser acompanhado por instrumento. Segundo Horácio (idem, 192-200), o coro deve defender sua individualidade como ator, só deve cantar no meio dos atos o que estiver intimamente ligado ao argumento, bem como deve aconselhar os bons, acalmar os irados, rogar aos deuses pelos desgraçados e louvar a paz e as leis. A isso, pode haver o acompanhamento de instrumentos, como a flauta, antes exclusiva à poesia lírica, pois ela pode dar o tom à ideia transmitida pelo coro. Em outras palavras, podemos entender o papel musical como aquele que expressa o tom volitivo-emocional, a valoração ao que se expressa.

A partir da epístola horaciana, o estudo da relação entre a dimensão visual e a verbal, ou entre artes plásticas e literatura, desenvolveu-se e chegou ao seu ápice nos séculos XVII e XIX. Pintores visavam efeitos dramáticos nos seus quadros e muitos poetas, por sua vez, eram conhecedores das artes ou mesmo pintores amadores.

7 Na edição brasileira de domínio público, vemos a seguinte tradução que evidencia ainda mais a aproximação de linguagens: "O elemento básico da tragédia é sua própria alma: a fábula; e só depois vem a pintura dos caracteres. Algo semelhante se verifica na pintura: se o artista espalha as cores ao acaso, por mais sedutoras que sejam, elas não provocam prazer igual àquele que advém de uma imagem com os contornos bem definidos." (sem data, cap. 6, 19-20, grifos nossos) 
No romantismo, a poética de Goethe era compatível com a visibilidade mais precisa. Encontramos tal afırmação, inclusive, nos escritos bakhtinianos, como, por exemplo, no texto "O romance de educação", no qual Bakhtin analisa a presença imagética nas obras do escritor alemão.

O ideal do movimento romântico de superar o percurso e as leis da razão por transporte ao mundo da fantasia, da imaginação, do sonho e do caos utiliza rupturas sonoras métricas (Victor Hugo, por exemplo, tornou o verso alexandrino mais flexível) e construções imagéticas contraditórias (recursos que serão usados de Goethe a Baudelaire e toda a modernidade. Este último, com o amplo registro de suas palavras, diversidade de seus ritmos e superabundância de suas imagens, proporcionou novas possibilidades de imagens da vida moderna à poesia) (VALERY, 1991; ELIOT, 1989).

Nessa perspectiva, ocorreu uma (re)aproximação das dimensões verbal, sonora e visual a partir das correntes poéticas, em especial a francesa, a qual, segundo Octavio Paz (1996, p. 36), "nos mostraram a correspondência entre ritmo e imagem poética. Mais uma vez: ritmo e imagem são inseparáveis" e que, por isso, "nos leva de volta ao ponto de partida: só a imagem poderá dizer-nos como o verso, que é frase rítmica, é também frase que possui sentido". Com isso, temos a musicalidade suave do parnasianismo, a música dissonante dos poemas simbolistas, a musicalidade própria da língua, de T. S. Eliot, a anarquia gráfica mallarmeniana, a poesia estranha, discordante e íntima de Pound, a verbivocovisualidade de Joyce e as experimentações futuristas de Maiakóvski, Khliébnikov e Krutchônykh com a proposta de uma nova linguagem, denominada transmental, a qual, ao privar a palavra de toda a sua carga semântica, evidencia-nos o sentido não como algo a priori da palavra ligado apenas ao conteúdo semântico, mas aberto e interligado diretamente com a articulação sujeito-leitor-ouvinte, o contexto e o falante, bem como os aspectos formais. A tudo isso converge a ideia de Octavio Paz (idem) de que o ritmo, a imagem e o significado (para não se confundir com o significado dicionaresco, diremos sentido) estão presentes e se revelam simultaneamente em uma unidade indivisível e compacta na frase poética, no verso. E acrescentamos: na linguagem, como temos entendido e proposto.

Ainda de acordo com Octavio Paz (1996, p. 26), tal abordagem poética é possível pela própria condição da poesia (da linguagem), pois o sentido que se apresenta como uma ideia:

[...] não é um objeto da razão, mas uma realidade que o poema revela numa série de formas fugazes, isto é, uma ordem e temporal. [...] Nossa apreensão é parcial e sucessiva. E é, além disso, simultânea: visual (imagens suscitadas pelo texto), sonora (tipografia: recitação mental) e espiritual (significados intuitivos, conceituais e emotivos). 
Como maior exemplo desse fenômeno de linguagem, temos, aqui no brasil, o projeto literário denominado Poesia Concreta desenvolvido pelo grupo Noigandres, composto por Augusto de Campos, Haroldo de Campos e Décio Pignatari. No esteio de Joyce, E. Cummings, Mallarmé, Pound, entre outros, os poetas concretos elaboram a concepção de linguagem verbivocovisual e definem o poema concreto como

[...] uma estrutura ótico-sonora irreversível e funcional, e, por assim dizer, geradora da ideia, criando uma entendida toda dinâmica, 'verbivocovisual' - é o termo de Joyce de palavras dúcteis, moldáveis, almagamáveis, à disposição do poema. (CAMPOS; PIGNATARI; CAMPOS, 1975, p. 34, grifos nossos).

Por esse viés, a palavra é tomada como uma unidade em si mesma, isto é, palavra-coisa, que possui dinamicidade. Assim, os concretistas organizam, em seu projeto literário, o material disponível (palavra, sílaba, fonema, som, fisionomia acústico-vocal-visual dos elementos linguísticos, grafia etc.), a concretude verbivocovisual da linguagem, de modo a explicitar a palavra-coisa como poema que traduz, de maneira metalinguística, a linguagem feito um objeto tridimensional dinâmico, uma célula viva, o que corresponderia, na teoria bakhtiniana, à ideia de "organismo vivo". Diante do contexto desse termo, verbivocovisual, é que Paula se apropria, metaforicamente, da noção joyceana e concreta para refletir acerca da relação de uma linguagem tridimensional proposta pelo Círculo.

Nas correntes poéticas da modernidade, sobretudo pela linguagem elevada à sua máxima potencialidade verbivocovisualidade,

A poesia coloca o homem fora de si e, simultaneamente, o faz regressar ao seu ser original: volta-o para si. O homem é a sua imagem: ele mesmo e aquele outro. Através da frase que é ritmo, que é imagem, o homem - esse perpétuo chegar a ser - é. A poesia é entrar no ser. (PAZ, 1996, p. 50).

E assim a poesia passa a se tornar consciência do que foi separado historicamente, no homem e na linguagem, e tenta reunir o elo perdido.

Nos estudos da linguagem, por sua vez, muitas questões desenvolvidas na literatura aparecem sendo abordadas de maneira metafórica e teórica. Destacamos, por exemplo, o próprio conceito de signo linguístico proposto por Saussure ${ }^{8}$. Para o linguista francosuíco, o signo é composto por significado e significante, em que o primeiro é o conceito e o segundo, a imagem acústica, a qual não se trata do som puramente físico, material, mas sim de uma impressão psíquica. E

8 Simultaneamente aos seus trabalhos, temos, na União Soviética, estudos que antecipam ideias presentes no CLG. Falamos, por exemplo, de Humboldt, que influenciou todo o pensamento da linguística russa nos séculos XIX e XX, incluindo o Círculo de Bakhtin. 
O caráter psíquico de nossas imagens acústicas aparece claramente quando observamos nossa própria linguagem. Sem movermos os lábios nem a língua, podemos falar conosco ou recitar mentalmente um poema. [...] Esse termo, que implica uma ideia de ação vocal, não pode convir senão à palavra falada, à realização da imagem interior no discurso. (SAUSSURE, 2006, p. 80, grifos nossos).

Retomamos as ideias de Paz (1996). Para ele, o lexema possui valor psicológico. As imagens, e acrescentamos o som, são produtos da nossa imaginação. Na retórica, esses fenômenos já foram classificados e nomeados: comparações, símiles, metáforas, jogos de palavras, paronomásias, símbolos, alegorias, mitos, fábulas, aliteração, assonância etc. No entanto, não se tratam de abstrações apenas por configurarem no plano psíquico. Conforme afirmado por Volóchinov (2013), no ensaio "O que é linguagem?", tudo o que está em nossa mente, a nossa própria consciência, é encarnada por algum material sígnico, seja ele imagens, palavras, sons e até mesmo representações motoras, tudo isso é o que o pensador russo denomina como linguagem interior.

De volta a Saussure, vemos que ele afirma, no Curso de Linguística Geral (2006), que o problema linguístico é, antes, um problema semiológico, pois a Linguística é parte de uma ciência geral dos signos, denominada por ele de Semiologia e estuda a vida dos signos no seio social. Nesse sentido, por estar atrelada a essa ciência geral, a Linguística está sujeita às leis que regem a Semiologia. Tal constatação explica a capacidade de um poema ou mesmo uma fala/escrita cotidiana produzir imagens e sons, bem como a de ter esse efeito em outras linguagens, visuais e sonoras, ou seja, de produzir palavras. Em outros termos, de poder "traduzir" uma linguagem em outra.

Em diálogo com essas correntes literárias, linguísticas e filosóficas é que a proposta filosófica de linguagem do Círculo de Bakhtin acontece. A possibilidade de acesso e conhecimento dos textos citados ao longo do trabalho em um contexto de perseguição e de censura de livros, pensamentos e teorias se dá devido ao fato de a formação do grupo contar com intelectuais de diversas áreas (a saber: biologia, física, poesia, música, literatura, filosofia, história) e tal constituição pode ser vista na elaboração da filosofia bakhtiniana, por meio de formulações teóricas e conceituais.

Observamos um dos raros momentos de delimitação conceitual a respeito da noção de linguagem - frequentemente, o Círculo volta-se para o enunciado - nas obras. No livro Estética da Criação Verbal, coletânea de escritos, temos, no texto "O problema do texto na linguística, na filologia e em outras ciências humanas", o apontamento para um sistema de linguagem única, que é inegável e está por trás de cada texto (entendido como um conjunto coerente de signos, logo, qualquer tipo de material), de modo que não pode e nem há textos puros. Bakhtin (2011, p. 311, grifos nossos) expõe que: 
Todo sistema de signos (isto é, qualquer língua), por mais que sua convenção se apoie em uma coletividade estreita, em princípio sempre pode ser codificado, isto é, traduzido para outros sistemas de signos (outras linguagens); consequentemente, existe uma lógica geral dos sistemas de signos, uma potencial linguagem das linguagens única (que, evidentemente, nunca pode vir a ser uma linguagem única concreta, uma das linguagens).

Tal acontecimento ocorre porque qualquer fenômeno que se manifeste como signo ideológico possui uma concretude material, não importa qual (cor, massa, som, corpo etc). Fora da encarnação em um determinado material, o signo, a construção enunciativa, torna-se falsa e abstrata. De acordo com Volóchinov (2017), em Marxismo e Filosofia da Linguagem, é preciso dado material organizado - no material ideológico da palavra, do signo, do desenho, das tintas, do som - para a expressão do fato objetivo.

Outro indício que norteia a tridimensionalidade da concepção de linguagem bakhtiniana é o recorrente uso, de forma metafórica, de conceitos e lexemas para caracterizar os fenômenos de língua(gem). Deparamo-nos com concepções advindas tanto de áreas da ciência (biologia e física) quanto das artes (teatro, arquitetura, música e literatura). No próprio Estética da Criação Verbal, mais especificamente no texto "O autor e o herói na atividade estética", Bakhtin dedica um subcapítulo para desenvolver o conceito de ritmo na categoria temporal do romance e outro de imagem externa para discutir a noção espacial. Além desses dois conceitos, expomos a seguir outros dois, Arquitetônica e tom, para ilustrar como são configurados na filosofia do Círculo.

A concepção de arquitetônica no pensamento bakhtiniano tem sido relacionada comumente a duas influências teóricas de campos distintos: a filosofia de Kant, por um lado; e o historiador das artes, Wölfflin, por outro. Na sua obra Conceitos fundamentais da história da arte (2019), o historiador utiliza o termo arquitetônica para se referir à essência das artes (escultura, arquitetura e pintura) como uma ideia de todo formal acabado e ideal. Já Kant, no terceiro capítulo da Crítica da Razão Pura (1983), emprega a noção de arquitetônica para pensar a organização sistemática de todo o conhecimento. Segundo o filósofo alemão, é próprio da razão do homem possuir uma arquitetônica. Essa é, por fim, a doutrina do saber científico no conhecimento humano.

Contudo, na filosofia da linguagem proposta pelo Círculo de Bakhtin, ambas as concepções são reformuladas para pensar a unidade do enunciado de cada sujeito no mundo ético e estético, tal qual afirma Campos (2015), citando Bakhtin (2003, XXXIV, p. 205):

[...] diferente dessa concepção de Kant, em que a arquitetônica é a doutrina do científico, Bakhtin demonstra que a arquitetônica é a alternativa teórica para pensar que "arte e vida não são a mesma coisa, mas devem tornar-se algo singular em mim, na unidade da minha responsabilidade". 
E é o que o filósofo russo faz ao estabelecer este conceito tanto nos textos "Arte e responsabilidade" e "O autor e o herói na atividade estética" quanto na obra Questões de literatura e estética (1988). Nela, inclusive, há uma variação no conceito, o qual Bakhtin denomina forma arquitetônica.

No pensamento bakhtiniano, arquitetônica pode ser entendida como aquela que "não ordena só os elementos espaciais e temporais, mas também os de sentido; a forma não é só espacial e temporal, mas também de sentido." (BAKHTIN, 2011, p. 127). Isto é, caracteriza-se pela organização "acabada" do enunciado, não de modo a priori, mas como uma construção única e irrepetível feita por um sujeito, este, enquanto um todo concluído. Na construção arquitetônica de um dado texto é que se articulam todos os elementos que o compõem, sempre na relação eu-outro.

Em Questões de literatura e estética (1988), o conceito é retomado em relação à forma composicional e à importância de definir as noções de cada concepção, pois, embora aquele conceito esteja estritamente ligado à forma composicional, ambos não se confundem, pois atuam em "camadas" distintas do enunciado. Por isso, o pensador russo explica que as formas arquitetônicas

[...] são as formas dos valores morais e físicos do homem estético, as formas da natureza enquanto seu ambiente, as formas do acontecimento no seu aspecto de vida particular, social, histórica, etc.; todas elas são aquisições, realizações, não servem a nada, mas se auto-satisfazem tranquilamente; são as formas da existência estética na sua singularidade. (BAKHTIN, 1988, p. 25).

Elas definem a imagem do autor externamente, sua assinatura do projeto de dizer, pois o situam na atuação no mundo ético e estético, no qual o sujeito está inserido de modo duplamente orientado. Por fim, Campos (2012) elucida as ideias gerais que emergem a partir dessa noção. Segundo a autora,

Essa distinção entre forma composicional e arquitetônica parte da ideia de que esse último conceito nasce de um pensamento que tem o ser humano como centro de valor, porque há um homem que fala, que se interroga e que procura estabelecer relações interativas, formulando perguntas e respostas diante dos acontecimentos da vida. Ao propor esse conceito, Bakhtin explica a necessidade de se fazer uma descrição da arquitetônica valorativa do viver o mundo, não com uma fundamentação analítica à frente, mas com um centro verdadeiramente concreto, espacial e temporal, do qual surgem valores, afirmações, ações reais, e onde os membros são pessoas reais, vinculadas entre si por meio de relações de um acontecimento concreto. (CAMPOS, 2012, p. 253). 
A construção da arquitetônica, por sua vez, tem como centro de apoio o sentido, ou seja, o tom valorativo que o sujeito tem ao expressar seu projeto de dizer. Ela materializa-se, por meio da entonação, em diversas maneiras - irônica, alegre, melancólica, etc. - de acordo com a posição volitiva-axiológica do falante na existência. Aqui, Bakhtin recorre ao campo da música para pensar a linguagem.

Na teoria musical, por tonalidade e tom, no plano teórico, são dois conceitos distintos, mas indissociáveis - semelhante às noções de enunciado e gênero discursivo na filosofia bakhtiniana. O primeiro, tonalidade, caracteriza-se por um sistema característico de sons, o qual se chama escala. A partir disso, tem tonalidade maior, menor, melódica ou harmônica. Essas tonalidades se realizam no tom. Assim, como há, no conjunto musical, vários tons, uma tonalidade pode ocorrer em mais de um tom. Por exemplo, uma tonalidade maior pode acontecer no campo de dó ou de ré. Mas, por esses conceitos estarem tão imbricados, na prática, confundem-se.

De volta à teoria bakhtiniana. Um enunciado é sempre pleno de tonalidades dialógicas, as quais o tornam compreensível, pois manifesta um ou vários tons. Por exemplo, em uma alusão, grosso modo, a ironia (tonalidade) pode ser usada em vários tipos de tom: superioridade, insatisfação, irritação.

O tom, essa carga emocional, é também passado de enunciado para enunciado e ecoa nas palavras durante as relações dialógicas, assim como ocorre com a entonação. Pois é por meio desta que se vinculam as tonalidades. De acordo com Bakhtin (2013), no texto Questões de estilística no ensino de línguas, a intensidade do tom pode ser enfraquecida dependendo da forma (entonação) de composição do enunciado, por exemplo, com relações lógicas, ou seja, a partir do uso de conjunções em períodos compostos, se comparado com o tom em períodos sem conjunções.

Na entonação, abarca-se as tonalidades e os tons, dialogicamente, de modo que definem e incidem no estilo e na autoria (a assinatura do sujeito), embora tal como enunciado, são definidas a partir de quem fala, o quê fala e para quem fala.

Assim como o conceito de entonação, a noção de tom e tonalidade aparecem, até com mais destaque, em Estética da Criação Verbal. No ensaio "O autor e o herói na atividade estética", Bakhtin (2011, p. 86, grifo nosso) aponta a relação entre a entonação e o tom:

O tom volitivo-emocional, embora vinculado à palavra e como que fixado à sua imagem sonora tonalizante, evidentemente não diz respeito à palavra mas ao objeto que esta exprime [a ideia, o sentido], mesmo que este não se realize na consciência como imagem visual; só pelo objeto assimila-se o tom emocional, mesmo que este se desenvolva junto com o som da palavra. 
O tom, bem como a entonação, diz respeito ao objeto, mas entendido de modo personificado pela força entonacional, como apontamos. Esse aspecto é reforçado pelo fato de o tom estar direcionado para a relação eu-outro, ou seja, por depender de quem e para quem fala. Podemos nos expressar em dado tom, compreendido de maneira diversa (em outro tom) pelo outro, pois soa axiologicamente diferente para o eu e para o outro.

\section{Considerações finais}

Diante dos indícios aqui mencionados, parece-nos pertinente conceber a noção bakhtiniana de linguagem de forma tridimensional. Poderíamos nos debruçar em outros conceitos, os quais igualmente advêm dos campos da música e das artes plásticas, mas que, devido ao espaço delimitado, centramo-nos aos dois expostos acima. Por exemplo: imagem de autor, polifonia, acento, dramaticidade, elemento visual, timbre, entonação e homofonia são algumas concepções que, em conjunto, constroem o que Paula tem designado como a tridimensionalidade verbivocovisual de linguagem do Círculo.

Ademais, os recentes desdobramentos da teoria, feitos por estudiosos das obras do Círculo, reforçam a pertinência da filosofia bakhtiniana para trabalhos que vão além da materialidade verbal. Estamos nos referindo aos trabalhos de Maria Teresa de Freitas, Solange Jobim e Souza e Sônia Kramer (2003), Anthony Wall (2014, 2015), Deborah J. Haynes (2008), Patrizia Calefato, Augusto Ponzio e Susan Petrilli (2007), Robert Stam (1989, 1992), Iris Zavala (1969, 2011), Tatiana Bubnova (2016), Graham Pechey (2007), Tim Beasley-Murray (2007).

A pesquisadora Beth Brait (2015), inclusive, propõe a concepção de enunciado verbo-visual, como articulado por duas linguagens de mesmas forças e importância que compõem o projeto discursivo do sujeito. No entanto, nossa proposta se distingue, pois: a) pensamos em uma concepção de linguagem como sistema, conforme indicado por Bakhtin em "O problema do texto na linguística, filologia e em outras ciências humanas", o qual reveste todo e qualquer enunciado, independente de sua materialidade; e b) propomos que há um terceiro elemento, não considerado, o sonoro/vocal. Assim, as dimensões verbal, vocal/sonora e visual se articulam indissociavelmente, conforme vimos apresentando no decorrer do texto.

Além disso, a dupla preocupação de Paula se volta tanto à noção de linguagem (fundada na noção aqui citada de "linguagem das linguagens", que semiotizaria, de maneira prototípica, as linguagens) quanto à materialização dessa tridimensionalidade verbivocovisual em qualquer enunciado (de que material semiótico for). Assim, mesmo um lexema verbal possui, em si, cunhado no signo verbal, uma dimensão acústica vocal/sonora, entoativa, que engata o lexema na cadeia discursiva; e uma dimensão visual mental, que remete à situação de comunicação real. O mesmo ocorre com enunciados de outras materialidades. O quadro "O Grito", de Munch, é um exemplo do quanto, pela expressão visual e pelo 
título verbal, a sonoridade se encontra expressa nos traços imagéticos; da mesma forma que a música de Beethoven revela sua polifonia linguística, como estudou Volóchinov no texto não traduzido para o português denominado Problemas da obra de Beethoven, de 1926, três anos antes da primeira versão de Problemas da Obra de Dostoiévski, de Bakhtin, vindo a público em 1929 (versão da tradução deste texto para o português do Brasil se encontra a caminho, realizada por Sheila Grillo e Ekaterina Volkova). Na primeira versão da obra de Bakhtin, talvez não por coincidência, há um ensaio mais contundente sobre a relação entre o verbal, o musical/vocal e o visual. Ensaio que não se encontra na versão reformulada de Problemas da Poética de Dostoiévski, dos anos 60 e que foi publicado na Rússia postumamente, como ensaio separado, em 1975, após a morte de Bakhtin e que se encontra na versão de Estética da Criação Verbal traduzida do francês no Brasil.

Considerando a produção dialogada do Círculo, as áreas de atuação de seus membros, o interesse em pensar a linguagem de maneira ampla, ainda que tomada a partir e por meio do estudo da literatura, é que compreendemos a concepção filosófica de linguagem bakhtiniana de forma tridimensional, pois, ao analisar o sujeito e como ele se manifesta na e pela linguagem, percebemos o quanto ele se concretiza (de acordo com Paz, ele é) de maneira verbivocovisual, como a vida, constituída de suas semioses.

\section{REFERÊNCIAS}

ARISTÓTELES. Arte Poética. Tradução Ana Maria Valente. Lisboa: Fundação Calouste Gulbenkian, 2008.

ARISTÓTELES. Arte Poética. Disponível em: http://www.dominiopublico.gov.br/ download/texto/cv000005.pdf. Acesso em: 24 ago. 2019.

ARISTÓTELES; HORÁCIO; LONGÍNQUO. A Poética Clássica. Tradução Bruna Jaime. 12. ed. São Paulo: Cultrix, 2005.

BAKHTIN, M. Problemas da Poética de Dostoiésvki. 5. ed. Rio de Janeiro: Forense Universitária, 2015.

BAKHTIN, M. Questões de Estilística no Ensino de Língua. Rio de Janeiro: 34, 2013.

BAKHTIN, M. Estética da Criação Verbal. Tradução Paulo Bezerra. 6. ed. São Paulo: Martins Fontes, 2011.

BAKHTIN, M. Questões de literatura e estética. São Paulo: Editora UNESP e HUCITEC, 1988. 
BAKHTIN, M.; DUVAKIN, V. Mikhail Bakhtin em diálogo - Conversas de 1973 com Viktor Duvakin. São Carlos: Pedro \& João Editores, 2008.

BAKHTIN (VOLOSHINOV). Discurso na Vida, Discurso na Arte (Sobre a Poética Sociológica). Tradução para fins acadêmicos de Carlos Alberto Faraco e Cristóvão Tezza, a partir da tradução inglesa de I. R. Titunik. Mimeo, s/d.

BRAIT, B. Literatura e Outras Linguagens. São Paulo: Contexto, 2015.

BUBNOVA, T. Do corpo à palavra - Leituras bakhtinianas. São Carlos: Pedro \& João Editores, 2016.

BUBNOVA, T. Voz, sentido e diálogo em Bakhtin. Tradução R. L. Baronas e Fernanda T. Bakhtinianas, São Paulo, ano 6, n. 1, p. 268-280, ago./dez. 2011.

CALEFATO, P.; PONZIO, A.; PETRILLI, S. Fundamentos de Filosofia da Linguagem. São Paulo: Vozes, 2007.

CAMPOS, M. I. B. A questão da arquitetônica em Bakhtin: um olhar para materiais didáticos de língua portuguesa. Filologia Linguística Portuguesa. v. 2, n. 14, p. 247-263, 2012.

CAMPOS, M. I. B. Compreensão sobre a arquitetônica em Bakhtin: fontes kantianas. Organon, Porto Alegre, v. 30, n. 59, p. 199-210, 2015.

CAMPOS, A. de; PIGNATARI, D. CAMPOS, H. de. Teoria da Poesia Concreta. São Paulo: Livraria Duas Cidades, 1975.

CASSOTI, R. S. Il linguaggio musicale nel circolo di Bachtin, Ivan Sollertinskij, Marija Judina. 2002. Tese (Doutorado em Estudos da Linguagem) - Universidade de Estudos de Bari, Bari, 2002.

ELIOT, T. S. Baudelaire. In: ELIOT, T. S. De poesia e poetas. São Paulo: Brasiliense, 1991.

ELIOT, T. S. Ensaios. Tradução Ivan Junqueira. São Paulo: Art Editora, 1989.

EMERSON, C. Os cem primeiros anos de Mikhail Bakhtin. Tradução Pedro Jorgensen Jr. Rio de Janeiro: DIFEL, 2003. 
FREITAS, M. T. A; JOBIM E SOUZA, S.; KRAMER, S. (org.). Ciências Humanas e Pesquisa Leituras de Mikhail Bakhtin. São Paulo: Cortez, 2003.

HAYNES, D. J. Bakhtin and the visual arts. Nova lorque: Cambridge, 2008.

KANT, I. Crítica da Razão Pura. Tradução Valerio Rohden e Udo Baldun Moosburguer. 2. ed. São Paulo: Abril, 1983.

MEDVIÉDEV, P. O Método Formal nos Estudos Literários. Tradução Sheila Grillo e Ekaterina Vólkova Américo. São Paulo: Contexto, 2012.

MORSON, G. S.; EMERSON, C. Mikhail Bakhtin - criação de uma prosaística. São Paulo: Edusp, 2008.

MURRAY-BEASLEY, T. Mikhail Bakhtin and Walter Benjamin - Experience and form. Nova York: Palgrave Macmillan, 2007.

OLIVEIRA, S. R. de. Ut pictura poesis: o fio de uma tradição. Cadernos de Linguística e Teoria da Literatura, [S. I.], n. 18-20, p. 129-144, dez. 2016. Disponível em: http://www. periodicos.letras.ufmg.br/index.php/cltl/article/view/10138/9054. Acesso em: 24 ago. 2019.

PAULA, L. de. Verbivocovisualidade: uma abordagem bakhtiniana tridimensional da linguagem. Projeto de Pesquisa em andamento. UNESP, 2017a.

PAULA, L. de. O enunciado verbivocovisual de animação - a valoração do "amor verdadeiro" Disney - uma análise de Frozen. In: FERNANDES JR., A.; STAFUZZA, G. B. (org.). Discursividades Contemporâneas - política, corpo e diálogo. Série Estudos da Linguagem. Campinas: Mercado de Letras, 2017b. p. 287-314.

PAULA, L. de; SERNI, N. M. A vida na arte: a verbivocovisualidade do gênero filme musical. Raído, Dourados, v. 11, n. 25, p. 178-201, jul. 2017. Disponível em: http://ojs.ufgd.edu.br/index.php/Raido/article/view/6507. Acesso em: 17 jul. 2017.

PAULA, L. de; FIGUEIREDO, M. H. de; PAULA, S. L. de. O Marxismo do/no Círculo. Slovo o Círculo de Bakhtin no contexto dos estudos discursivos. Curitiba: Appris, 2011.

PAULA, L. de; STAFUZZA, G. Círculo de Bakhtin - concepções em construção. Campinas: Mercado de Letras, 2019. (Série Bakhtin: inclassificável, v. 4). 
PAULA, L. de; STAFUZZA, G. Círculo de Bakhtin - pensamento interacional. Campinas: Mercado de Letras, 2013. (Série Bakhtin: inclassificável, v. 3).

PAULA, L. de; STAFUZZA, G. Círculo de Bakhtin - diálogos (in)possíveis. Campinas: Mercado de Letras, 2012. (Série Bakhtin: inclassificável, v. 2).

PAULA, L. de; STAFUZZA, G. Círculo de Bakhtin - teoria inclassificável. Campinas: Mercado de Letras, 2010. (Série Bakhtin: inclassificável, v. 1).

PAZ, O. O arco e a Lira. Tradução Olga Savary. Rio de Janeiro: Nova Fronteira, 1982.

PAZ, O. Signos em rotação. Tradução Sebastião Uchoa Leite. São Paulo: Editora Perspectiva, 1996.

PECHEY, G. Mikhail Bakhtin - The word in the world. Nova York: Routledge, 2007.

SAUSSURE, F. Curso de Linguística Geral. São Paulo: Cultrix, 2006.

STAM, R. Bakhtin - Da Teoria Literária à Cultura de Massa. São Paulo: Ática, 1992.

STAM, R. Subversive Pleasures - Bakhtin, Cultural Criticism, and Film. London: Johns Hopkins University Press, 1989.

TCHUDAKÓVA, M. Trabalhos Novos. 2003-2006. Moscou: Vriémia, 2007.

VALERY, P. Situação de Baudelaire. In: VALERY, P. Variedades. Tradução Maiza Martins de Siqueira. São Paulo: Iluminuras, 1991.

VOLÓCHINOV, V. A Construção da Enunciação e Outros Ensaios. São Carlos: Pedro \& João Editores, 2013.

VOLÓCHINOV, V. Marxismo e Filosofia da Linguagem. Rio de Janeiro: 34, 2017.

WALL, A. La place du lecteur - Livres et lecture dans la peinture française du XVIIle siècle. Rennes: Presses universitaires de Rennes, 2014.

WALL, Anthony. A bisbilhotice na pintura. Bakhtiniana. v. 11, n. 1, pp. 228-263, nov. 2015. 
WÖLFFLIN, H. Conceitos fundamentais da história da arte. São Paulo: Martins Fontes, 2019.

ZAVALA, I. M. Las Posmodernidad y Mijail Bajtin - Uma poética dialógica. Madrid: EspasaCalpe, 1969.

ZAVALA, I. M. Tango - Música, cuerpo y sensualidade. España: Montesinos, 2011.

ZEMTSOV, I. Linguagem política soviética. Londres: OPI, 1985. 